\title{
Design and Testing of PMSM for Aerospace EMA Applications
}

\author{
P. Giangrande ${ }^{1}$, V. Madonna ${ }^{1}$, G. Sala ${ }^{1}$, A. Kladas ${ }^{2}$, C. Gerada ${ }^{1,3}$, M. Galea ${ }^{1,3}$ \\ ${ }^{1}$ Power Electronics, Machines and Control Group, University of Nottingham, UK, p.giangrande@nottingham.ac.uk \\ ${ }^{2}$ School of Electrical and Computer Engineering, National Technical University of Athens, Greece \\ ${ }^{3}$ School of Aerospace, University of Nottingham Ningbo, China
}

\begin{abstract}
The more-electric aircraft initiative represents an important technology step-change for the aircraft industry. The reduction of both fuel consumption and environmental impact are leading to alternative solutions for actuating the flight control surfaces. The traditional hydraulic systems, are progressively being replaced with electrically powered actuators. In this scenario, electromechanical actuators are gaining an ever-increasing importance as enabling technology for next generation aircraft. This paper presents the design and testing of a permanent magnet synchronous motor driving a linear geared electromechanical actuator for commercial aircraft. The experimental results are discussed throughout the paper and compared to the finite element ones obtained at the design stage. Finally, the machine is integrated into the mechanical drivetrain and the electromechanical actuator performance is evaluated through experimental tests carried out on a purpose-built mechanical demonstrator for achieving a high technology readiness level.
\end{abstract}

Keywords - More-Electric Aircraft, Electromechanical Actuator, Permanent Magnet Synchronous Motor, Minimum Time Trajectory, Technology Readiness Level.

\section{INTRODUCTION}

In conventional aircraft, the energy stored in the fuel is converted into propulsive power by the gas turbine engine. A small amount of this power is extracted from the turbine and transformed in the hydraulic, mechanical, pneumatic and electrical counterparts, also referred to as secondary power sources [1]. The energy consumption of these sources is approximately $5 \%$ of the total fuel burnt during the flight [2]. For conventional aircraft, the secondary power systems are usually employed for

- Pneumatic power: it supplies both the environmental control unit and the de-ice system and it is obtained by bleeding air from the gas turbine [3].

- Electric power: it is produced by a three-stage wound-field synchronous generator coupled to the main engine shaft by means of a gearbox and it is commonly used for powering avionics and lighting systems [4].

- Mechanical power: it is extracted from the gas turbine shaft by way of a gearbox and it operates oil and fuel pumps [5].

- Hydraulic power: it actuates the flight controls and it is provided by hydraulic circuits, which are pressurized using hydraulic pumps driven by the engine through a gearbox [6].

In the past few decades, significant progresses have been made in the more-electric aircraft (MEA) technologies, especially in terms of secondary power sources. Indeed, the presence of traditional hydraulic, pneumatic and mechanical systems is being progressively reduced and replaced by electrical counterparts [7]. Outstanding examples of aircraft embracing the MEA concept are represented by the civil Boeing 787 and Airbus 380, and the military aircraft Lockheed F35 [2].

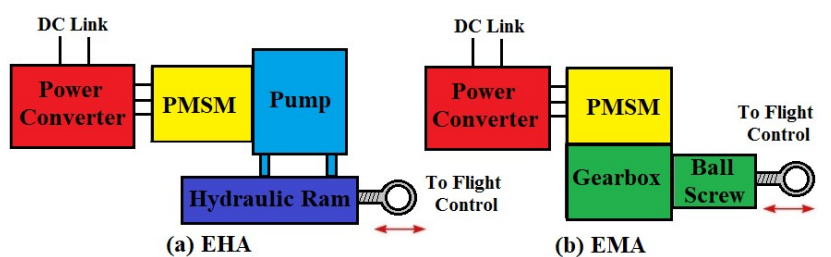

Fig. 1. Electrically powered actuators: (a) EHA and (b) EMA.

For on the flight control actuation, the heavy and not very versatile hydraulic systems are substituted with electrically powered actuators, such as electro-hydrostatic actuators (EHAs) [8-10] and electromechanical actuators (EMAs) [11-13]. In the EHAs, the electric power feeds an electric drive, which is mechanically coupled to a hydraulic pump, as depicted in Fig. 1(a). Thus, hydraulic power is locally generated for driving the flight control surface. For the EMAs, a mechanical drivetrain (e.g. gearbox and/or ball screw) is placed between the electric drive and the flight control surface, as schematically outlined in Fig. 1(b). Both EHAs and EMAs are currently installed on commercial aircraft. For instance, Boeing 787 adopts EMAs for landing gear brakes and spoiler surfaces [14], whilst, EMAs are used for actuating the slats, on the Airbus A380 [15]. According to a recent study, the adoption of EHAs for ailerons and elevators actuation led to a weight reduction of about $1500 \mathrm{~kg}$, on the Airbus A380 [16]. Despite the local hydraulics and the higher maintenance costs, the mixed solution represented by the EHAs is presently more widespread than the EMAs, because of the well-established "know-how" regarding hydraulic systems [16]. In fact, the risk of failure (e.g. jamming) and the lack of reliability data restrict the EMAs employment [14]. Nevertheless, EMAs represent a key technology, which is gaining interest due to its higher efficiency and further weight reduction compared to EHAs [17].

Among the electrical machines adopted in aerospace applications, permanent magnet synchronous machines (PMSMs) are a common choice for EMAs since they are characterized by high-power density and excellent efficiency [18-22]. In this paper, the design of a PMSM integrated into a linear geared EMA for flight control surface is presented. Finite element (FE) analysis is used for finalizing the design and investigating the PMSM behaviour during no-load and load conditions. Before integrating the PMSM prototype into the mechanical drivetrain, experimental tests are performed on the machine, in order to validate its design. Finally, the linear geared 
EMA is assembled and experimentally tested on a purpose-built demonstrator, which consists in a first order lever having a commercial linear actuator on one end (i.e. load side) and the EMA on the other end (i.e. actuation side). This mechanical structure allows to properly load the EMA by emulating the real operating conditions and increasing the technology readiness level (TRL) of the prototype. Finally, the EMA performance under minimum time trajectory position control are evaluated and the related experimental results are commented.

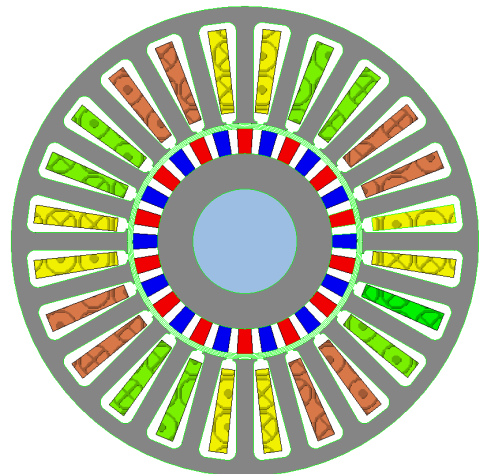

Fig. 2. Geometry and winding layout of the 24 slots / 28 poles PMSM.

\section{PMSM DESIGN AND CONSIDERATIONS}

Considering the application under analysis, the electric motor is required to deliver $4 \mathrm{Nm}$ at $800 \mathrm{rpm}$ by using a natural air cooling system. In addition, to comply with the limited available space, the axial length and the outer diameter of the stator core should not exceed $50 \mathrm{~mm}$ and $90 \mathrm{~mm}$ respectively. According to these constraints, the design is performed by a FE aided optimization. A preliminary trade-off study is carried out for selecting the appropriate slots/poles combination. In order to maximize the torque density, a 24 slots / 28 poles arrangement is chosen [23]. High fill-factor and short end-windings are achieved by adopting a single-layer concentrated winding, as shown in Fig. 2 [24]. This winding configuration contributes to lower the copper losses, reducing the amount of heat to be dissipated. Every phase winding consists in 4 series-connected coils made of 24 turns each.

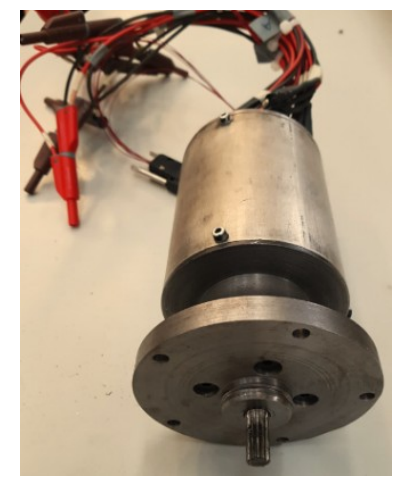

Fig. 3. 24 slots / 28 poles PMSM prototype.

In terms of materials, a silicon steel alloy (i.e. M235-35A with $1.4 \mathrm{~T}$ saturation flux density) is used for both the stator core (laminated stack) and the rotor back-iron (solid block). Samarium-cobalt permanent magnets are preferred to the neodymium-iron-boron typology, due to a higher operating temperature [25]. The permanent magnets are mounted on the rotor surface and, because of the relatively low rated speed, no retaining sleeve is installed. Finally, a 304 stainless steel is adopted for the solid shaft, while the smooth housing (i.e. without cooling fins) is made of aluminum. Fig. 3 shows the manufactured PMSM prototype, whose parameters are summarised in Table I. Preliminary tests are performed under no-load and load conditions on the PMSM prototype for validating the FE design. The experimental results are provided in the next sub-sections, along with the FE ones.

TABLE I. PMSM PROTOTYPE PARAMETERS

\begin{tabular}{|c|c|}
\hline Parameter & Value \\
\hline Rated Speed [rpm] & 800 \\
\hline Rated Torque [Nm] & 4 \\
\hline Rated Current [ $\left.\mathrm{A}_{\mathrm{pk}}\right]$ & 8 \\
\hline Stack Length [mm] & 40 \\
\hline Stator Outer Diameter [mm] & 90 \\
\hline Turns per Coil [-] & 24 \\
\hline Coils per Phase [-] & 4 \\
\hline
\end{tabular}

\section{A. PMSM-No-load performance}

The flux density map and the flux lines distribution at rated speed (i.e. $800 \mathrm{rpm}$ ) are determined via FE simulations in the commercial package Magnet-Infolytica. The corresponding results are presented in Fig. 4. At no-load conditions, the PMSM reveals a very low magnetic saturation level (i.e. its operating point is well below the knee region of the $\mathrm{B}-\mathrm{H}$ curve).

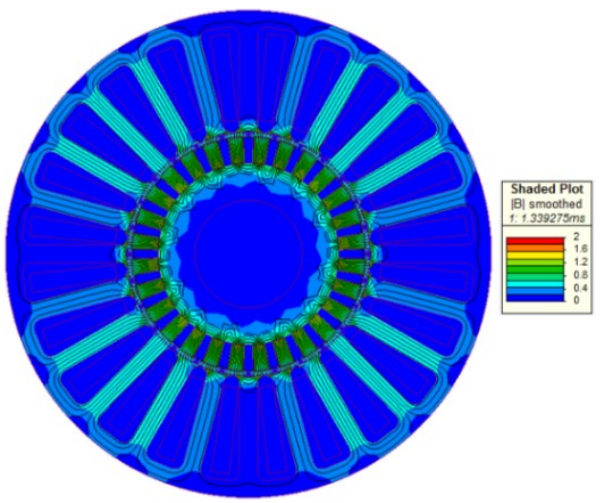

Fig. 4. Flux density map and flux lines distribution at $800 \mathrm{rpm}$.

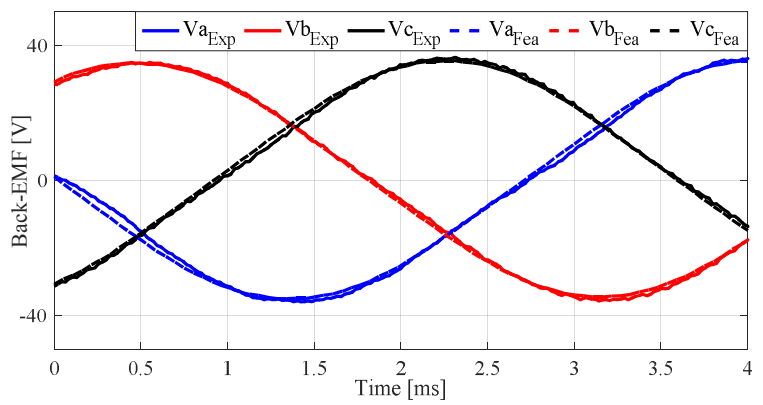

Fig. 5. Comparison between experimental (solid line) and FE (dashed line) back-EMFs at $800 \mathrm{rpm}$.

The actual back-EMFs are also measured when the PMSM prototype is back-driven by a commercial drive. The comparison between experimental and FE back-EMFs at rated speed is shown in Fig. 5, where the solid lines refer to the measured waveforms, whilst the dashed lines indicate the simulated ones. Despite the noise measurement, a good match can be observed from the results reported in Fig. 5. Based on the FE outcomes, 
the fundamental amplitude of line-to-neutral back-EMF is equal to $24.37 \mathrm{~V}_{\mathrm{rms}}$, whereby the voltage constant is $30.4 \mathrm{mV}_{\mathrm{rms}} / \mathrm{rpm}$. Instead, the measured values are $24.4 \mathrm{~V}_{\mathrm{rms}}$, and $30.5 \mathrm{mV}_{\mathrm{rms}} / \mathrm{rpm}$ respectively, with a $0.33 \%$ mismatch. The total harmonic distortion (THD) of the Back-EMF is calculated performing the Fourier series transformation. When the FE waveforms are considered, the THD is equal to $3.14 \%$, whereas a $6 \%$ THD is obtained in case of measured Back-EMFs.

\section{B. PMSM-Load performance}

The rated torque (i.e. $4 \mathrm{Nm}$ ) is developed by feeding the PMSM with the rated $8 \mathrm{~A}_{\mathrm{pk}}$ phase current. The flux density map and the flux lines distribution during full-load condition are depicted in Fig. 6, while Fig. 7 shows the FE instantaneous torque.

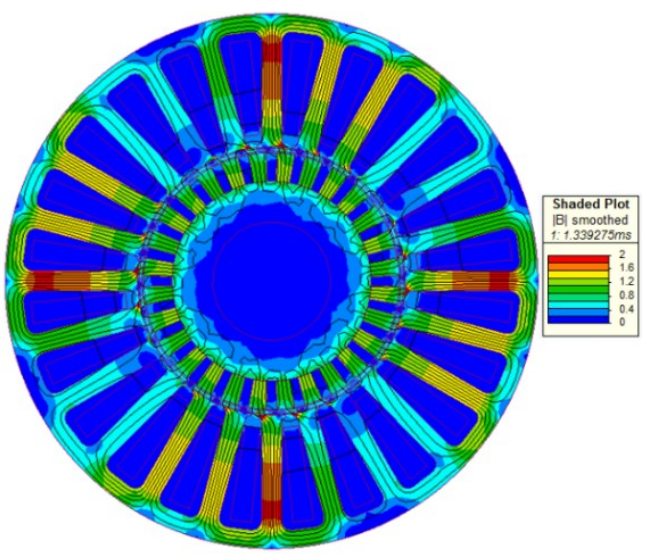

Fig. 6. Flux density map and flux lines distribution at $8 \mathrm{~A}_{\mathrm{pk}}$ and $800 \mathrm{rpm}$.

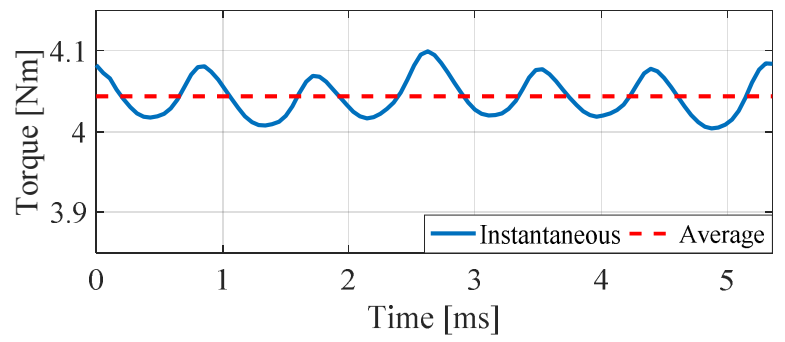

Fig. 7. Torque developed at $8 \mathrm{~A}_{\mathrm{pk}}$ and $800 \mathrm{rpm}$ : a) instantaneous value (solid blue line) and b) average value (red dashed line).
Analysing Fig. 6, an appreciable magnetic saturation level is attained in both the loaded teeth and the tooth shoe area. Taking into account that the EMA operates with a short-time duty-cycle and the full-load condition is not a continuous service operating mode, the reached level of magnetic saturation is acceptable for the application under study, albeit it has a relatively high value [26]. The average torque generated at rated current is equal to $4.04 \mathrm{Nm}$ (red dashed line in Fig. 7), whilst the instantaneous torque (blue solid line in Fig. 7) features a $4.7 \%$ ripple. The PMSM torque-current characteristic is also validated by experimental tests. Fig. 8 presents the comparison between FE and measurement results highlighting a good match. According to the FE findings, the PMSM torque constant is equal to $0.505 \mathrm{Nm} / \mathrm{A}_{\mathrm{pk}}$, while the post-processing of the experimental data provides a torque constant value of $0.496 \mathrm{Nm} / \mathrm{A}_{\mathrm{pk}}$ (i.e. with a $1.64 \%$ mismatch).

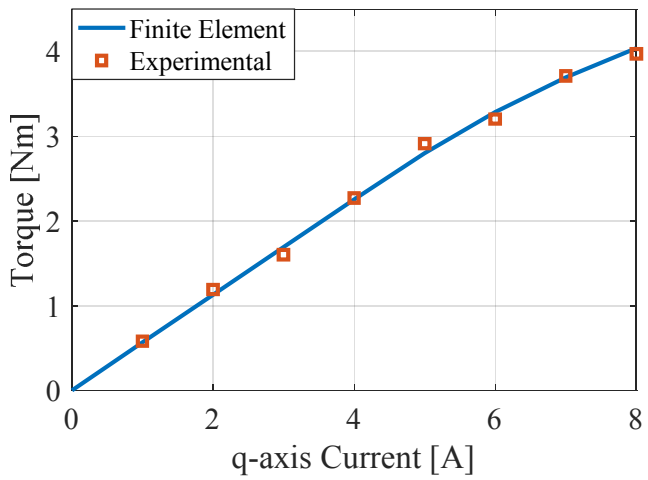

Fig. 8. Torque Vs $q$-axis current characteristic: experimental (red squares) and FE (blue solid line).

\section{MINIMUM TIME TRAJECTORY AND PMSM POSITION CONTROL}

The EMA integration tests were preceded by an experimental test campaign aiming to evaluate the PMSM performance in 'standalone' mode (i.e. without mechanical drivetrain) and position control operations. The experimental investigations presented in this work are carried out using a dSPACE 1104 control platform, while the PMSM is supplied by a commercial inverter with $270 \mathrm{~V}$ DC link voltage.

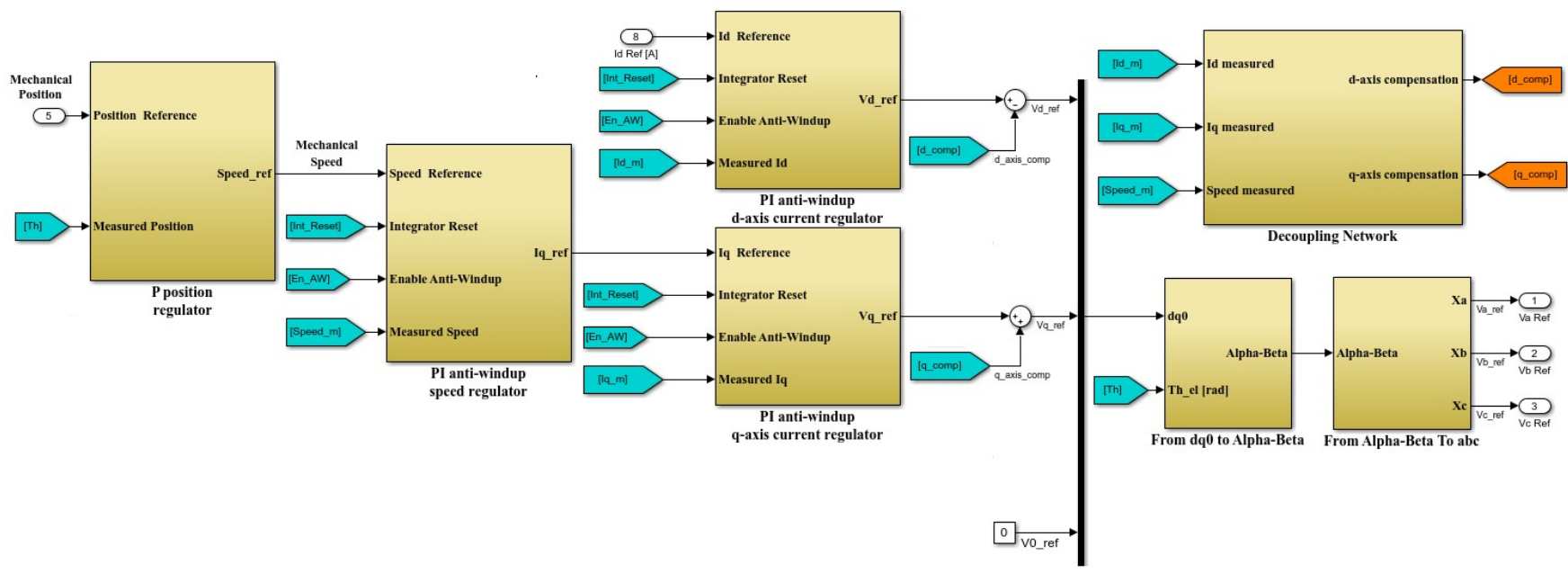

Fig. 9. Position control scheme diagram implemented in Matlab/Simulink environment and built on DS1104 microprocessor board. 
The control scheme is implemented in Matlab/Simulink environment and a cascaded architecture is used for controlling the PMSM position, as illustrated in Fig. 9. Considering the cascaded structure, the inner loops (i.e. current loops) supervise the $d$ - and $q$-axis current components by means of two proportional-integral controllers; the outer loop (i.e. speed loop) consists of a proportional-integral controller, which regulates the PMSM speed; the outermost loop (i.e. position loop) controls the shaft position using a proportional controller [27]. The $d$-axis current component set-point is set equal to zero (i.e. field weakening operations are not analysed in this study). The PMSM position tracking is based on a reference signal determined by a minimum time trajectory algorithm [28]. The trajectory set-points are defined by: 1) the final position, 2) the maximum speed and 3) the maximum acceleration. Starting from the initial position (commonly assumed equal to zero), the maximum acceleration is developed until the speed reaches its maximum value, then the trajectory is followed at maximum speed. Approaching the end position, the shaft slows down with the maximum deceleration, until the speed attains the null value.
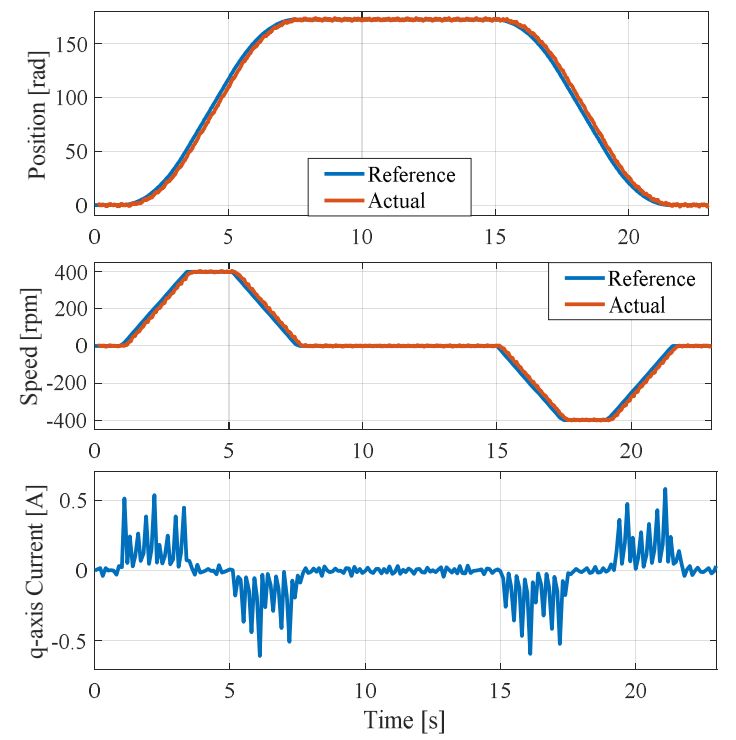

Fig. 10. Experimental results of the PMSM position control with 27.5 mechanical revolutions as final position at no-load: a) shaft position (top sub-plot), b) shaft speed (middle sub-plot) and c) $q$-axis current component (bottom sub-plot).

According to its mission profile, the EMA is required to extend, hold the achieved position and then retract to the rest position. For this reason, the minimum time trajectory is programmed for performing these three stages of the EMA mission. For the first experiment on the PMSM prototype, the chosen parameters of the minimum time trajectory are: 1) 27.5 mechanical revolutions as the final position, 2) $400 \mathrm{rpm}$ as maximum speed (i.e. half of the rated speed) and 3) $57.5 \mathrm{rad} / \mathrm{s}^{2}$ as maximum acceleration. From the EMA point of view, these parameters allow completing a $15 \mathrm{~mm}$ stroke in about $7.5 \mathrm{~s}$, as explained in the next section. The PMSM position is controlled at no-load (i.e. the shaft is not coupled to any mechanical device). Fig. 10 summarizes the results relative to this first experiment. In particular, it shows the shaft position and speed, along with the $q$-axis current component. Analysing the top sub-plot in Fig. 10, a modest position tracking error is observable during the extension and the retraction stages (i.e. position transients), whereas it is practically negligible at steady-state. Although the transient tracking error, there is an overall good match between reference and measured positions. For the second experiment, the minimum time trajectory parameters are selected in order to enable the EMA rod-end to cover $30 \mathrm{~mm}$ stroke in $7.5 \mathrm{~s}$ (for more details on the EMA drivetrain structure please refer to the next section). Hence, the PMSM final position is set equal to 55 mechanical revolutions, with a transient profile at $800 \mathrm{rpm}$ maximum speed (i.e. rated speed) and $115 \mathrm{rad} / \mathrm{s}^{2}$ maximum acceleration.

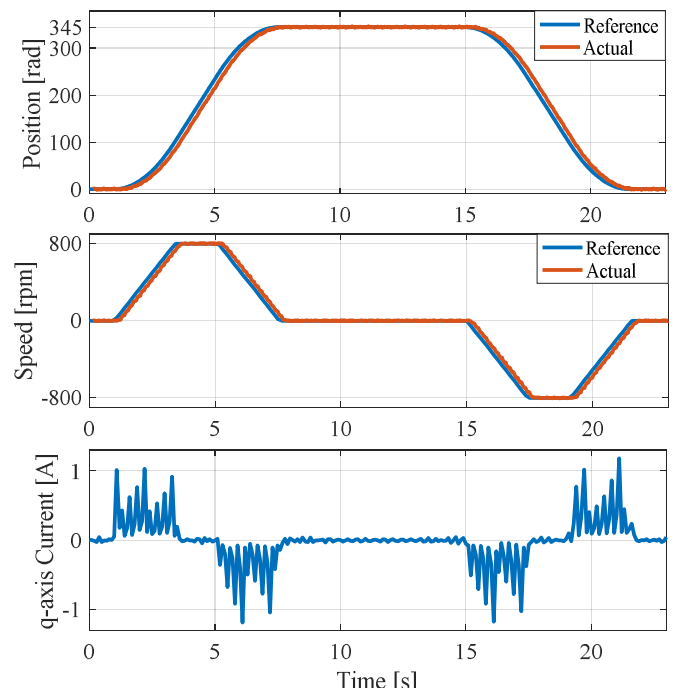

Fig. 11. Experimental results of the PMSM position control with 55 mechanical revolutions as final position at no-load: a) shaft position (top sub-plot), b) shaft speed (middle sub-plot) and c) $q$-axis current component (bottom sub-plot).

Fig. 11 reports the results of the second experiment (at no-load). In this case, the tracking error during transient is slightly higher compared to the first experiment. Nevertheless, the actual position tracks the trajectory set-point with reasonable accuracy. Both Fig. 10 and Fig. 11 prove the effectiveness of the implemented position control and the resulting performance are acceptable for moving forward to the EMA testing. It is noteworthy to point out that the oscillations on the $q$-axis current component (in both investigated cases) are mainly due to the poor capability of the controller to regulate the typical low current values at no-load condition.

\section{EMA DESCRIPTION AND PERFORMANCE}

Due to the safety critical nature of the application under analysis, the reliability requirements are met by using the actuator redundancy concept [11]. Indeed, in the real application, multiple EMAs act on the same flight control surface and if a fault occurs on one of them, the mission profile is completed by the remaining EMAs. The drivetrain of the linear geared EMAs considered in this work consists of two stages: 1) the gearbox, which enhances the torque produced by the PMSM and 2) the ball screw, which converts the rotational motion of the gearbox output shaft in linear motion of the EMA rod-end. The gearbox features a 11:1 step-down ratio, whilst the ball screw's transmission ratio is equal to $1047 \mathrm{rad} / \mathrm{m}$ (i.e. $6 \mathrm{~mm}$ pitch). In order to evaluate the EMA performance in a relevant environment (i.e. meeting the requirements for a high TRL), the 
assembled EMA is tested on the mechanical demonstrator depicted in Fig. 12.

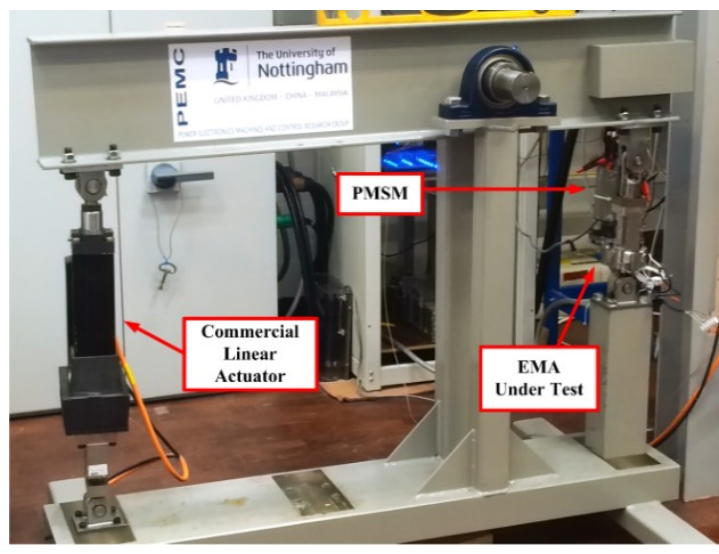

Fig. 12. Experimental setup for loading the EMA under test.
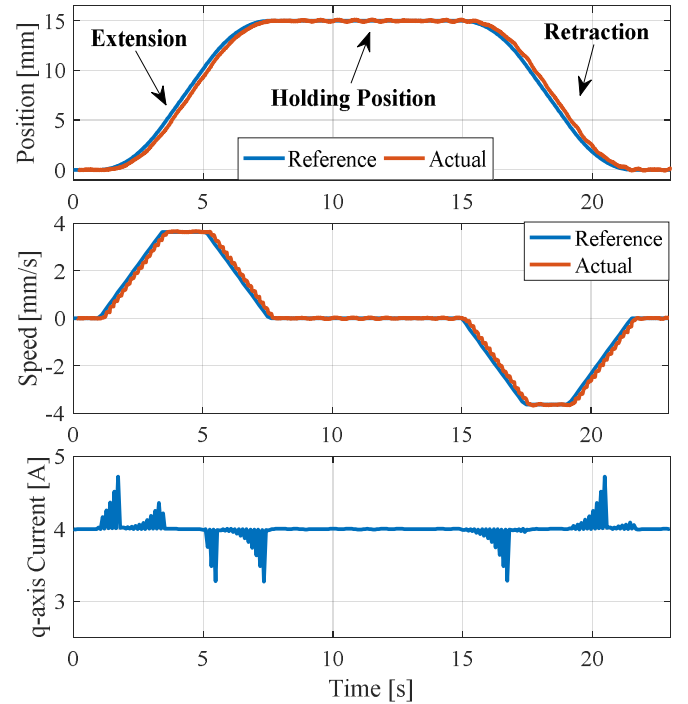

Fig. 13. Experimental results of the EMA position control with $15 \mathrm{~mm}$ position reference at half of the rated torque: a) rod-end position (top sub-plot), b) rod-end speed (middle sub-plot) and c) PMSM $q$-axis current component (bottom sub-plot).

The mechanical structure allows to emulate the actual load conditions and it is represented by a first order lever with off-centre fulcrum. The linear geared EMA under test (right-hand side of Fig. 12) is connected to the short end arm of the lever (520 mm long). Similarly, a commercial linear actuator (left-hand side of Fig. 12) is mounted at the end of the long arm (i.e. $970 \mathrm{~mm}$ ) to develop the load force. The EMA rod-end position is measured by means of a linear variable differential transformer (LVDT), while a strength gauge is used for measuring the force. The EMA position is controlled by using a minimum time trajectory algorithm for generating the set-point signal, as described in Section III. All experiments are carried out under load conditions, with a load force of about $7 \mathrm{kN}$, which corresponds at half of the EMA rated force. Thus, the designed PMSM operates at half of the rated torque (i.e. $2 \mathrm{Nm}$ ). The load force is applied when the EMA rod-end is still in the rest position (i.e. $0 \mathrm{~mm}$ ) and it continues to be active throughout the stroke until the trajectory is completed. The trajectory consists of an extension performed in $7.5 \mathrm{~s}$ and followed by a holding position period of $8 \mathrm{~s}$. Finally, the EMA rod-end retracts to the rest position in about $7.5 \mathrm{~s}$. Two experiments with different parameters for minimum time trajectory are presented. In the first experiment, the EMA covers a stroke of $15 \mathrm{~mm}$ (i.e. final position) with $3.64 \mathrm{~mm} / \mathrm{s}$ and $1.5 \mathrm{~mm} / \mathrm{s}^{2}$ maximum speed and acceleration respectively. Fig. 13 summarizes the results of the first experiment, where the position and speed of the EMA rod-end are shown along with the $q$-axis current component of the PMSM. Looking at Fig. 13, the EMA is capable to successfully complete its mission, although some oscillations are present on the linear speed. At steady-state position, the tracking error is very small and the load force is properly counteracted by the EMA. During the position transient (i.e. extension and retraction stages), the tracking error is higher, but always lower than $0.2 \mathrm{~mm}$ (mismatch $<1.35 \%$ ).
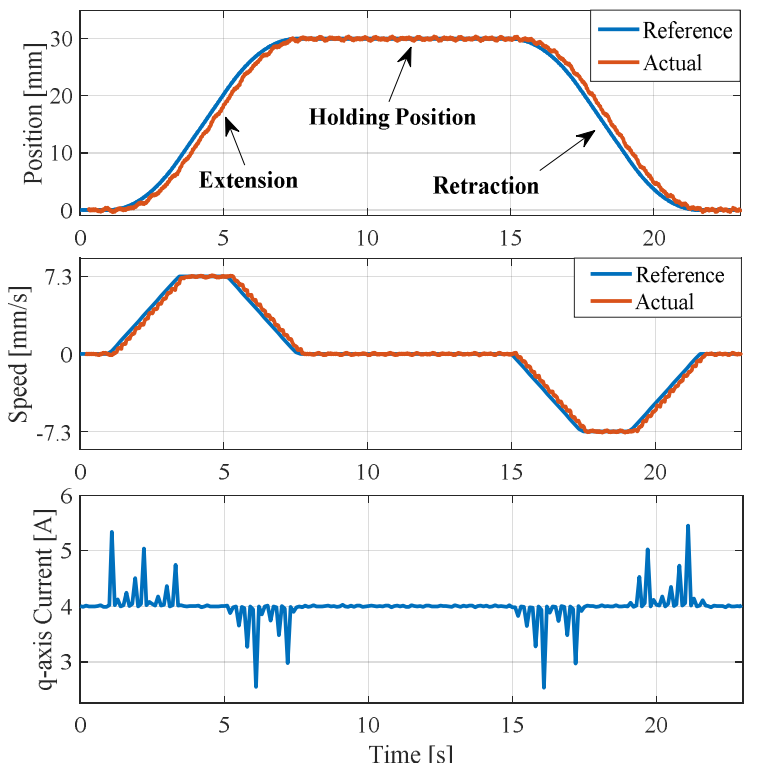

Fig. 14. Experimental results of the EMA position control with $30 \mathrm{~mm}$ position reference at half of the rated torque: a) rod-end position (top sub-plot), b) rod-end speed (middle sub-plot) and c) PMSM $q$-axis current component (bottom sub-plot)

For the second experiment, the same load force is produced (i.e. $7 \mathrm{kN}$ ) by the commercial linear actuator, whereas the minimum time trajectory parameters are doubled. Hence, the EMA rod-end is required to cover $30 \mathrm{~mm}$ stroke with a maximum speed of $7.28 \mathrm{~mm} / \mathrm{s}$ and a $1.5 \mathrm{~mm} / \mathrm{s}^{2}$ maximum acceleration. Fig. 14 reports the results obtained under these constraints, showing that the EMA is still fulfilling the mission requirements. In this case, during extension and retraction, the position tracking error is slightly higher compared to the previous experiment and more oscillations affect the measured waveforms. However, the discrepancy between reference and measured position is always lower than $0.27 \mathrm{~mm}$ (mismatch $<0.9 \%$ ). Despite the performance during transient, both position and load are properly held at steady-state with a minimal tracking error. The results provided by Fig. 13 and Fig. 14 reveal the EMA capability of working in operating conditions similar to the real application ones. Overall the outcomes of these tests is satisfactory. Further work is required in terms of fine-tuning of the control loops aiming to improve the dynamic performance by minimizing the position tracking error. This will be reported in future publications. 


\section{CONCLUSIONS}

In this paper, the design of a PMSM integrated to a linear geared EMA for flight control surface was presented. The PMSM performance was evaluated via FE analysis in both no-load and full-load conditions. The PMSM prototype was tested in order to validate the design outcomes and a good agreement between FE and experimental results was found. In particular, a $0.33 \%$ and a $1.64 \%$ mismatches on the voltage and torque constants were respectively detected. Before integrating the designed PMSM into the mechanical drivetrain, its performance was experimentally investigated by implementing a position control based on the minimum time trajectory algorithm. Two sets of minimum time trajectory parameters were adopted and in both cases the PMSM was capable of performing the required trajectories with a reasonable tracking error. Finally, the linear geared EMA was assembled and tested using a purpose-built demonstrator. The demonstrator allowed to properly load the EMA for verifying its performance in a relevant environment, which increases the prototype TRL. The test campaign carried out on the demonstrator proved the EMA capability in fulfilling its mission (i.e. extension + holding position + retraction) with several stroke's lengths. Despite the good performance in terms of position tracking error and holding force at steady-state position, the dynamic performance requires some improvements. More experiments are scheduled for testing the EMA at full-load force and minimizing the tracking error during transient.

\section{ACKNOWLEDGMENT}

Part of this work was funded by the INNOVATIVE doctoral programme. The INNOVATIVE programme is partially funded by the Marie Curie Initial Training Networks (ITN) action (project number 665468) and partially by the Institute for Aerospace Technology (IAT) at the University of Nottingham.

Part of this work was also supported by the Ningbo Science \& Technology Bureau under Grant 2013A31012.

\section{REFERENCES}

[1] P.W Wheeler, J.C. Clare, A. Trentin, et al. "An overview of the more electrical aircraft", in Journal of Mechanical Engineering Science, 2013.

[2] V. Madonna, P. Giangrande, and M. Galea, "Electrical Power Generation in Aircraft: review, challenges and opportunities," in press on IEEE Transactions on Transportation Electrification, DOI: 10.1109/TTE.2018.2834142, 2018

[3] J.A. Rosero, J.A. Ortega, E. Aldabas, et al. "Moving towards a more electric aircraft", in IEEE Aerospace and Electronic Systems Magazine, vol. 22, pp. 3-9, 2007.

[4] C.I. Hill, S. Bozhko, Y. Tao, P. Giangrande, and C. Gerada, "More Electric Aircraft Electro-Mechanical Actuator Regenerated Power Management," in 2015 IEEE International Symposium on Industrial Electronics, pp. 337-342, 2015.

[5] P.W Wheeler and S. Bozhko, "The more electric aircraft technology and challenges", in IEEE Electrification Magazine, 2014.

[6] M. Villani, M. Tursini, G. Fabri et al. "Electromechanical actuator for helicopter rotor damper application", in IEEE Transaction on Industry Application, , vol. 50, n. 2, pp. 1007-1014, March 2014.

[7] C. Sciascera, P. Giangrande, L. Papini, C. Gerada and M. Galea "Analytical Thermal Model for Fast Stator Winding Temperature Prediction," in IEEE Transactions on Industrial Electronics, vol. 64, n. 8, pp. 6116-6126, March 2017.

[8] G. Altare, A. Vacca and C. Richter, "A Novel Pump Design for an Efficient and Compact Electro-Hydraulic Actuator", in IEEE Aerospace Conference, 2014.
[9] A. Al-Timimy, M. Degano, Z. Xu, G. Lo Calzo, P. Giangrande, M. Galea, C. Gerada, H. Zhang and L. Xia, "Trade-off analysis and design of a high power density PM machine for flooded industrial pump," in 2016 IECON, pp. 1744-1749, 2016.

[10] A. Al-Timimy, M. Degano, P. Giangrande, G. Lo Calzo, Z. Xu, M. Galea, C. Gerada, H. Zhang, and L. Xia, "Design and optimization of a high power density machine for flooded industrial pump," in 2016 International Conference on Electrical Machines, pp. 1480-1486, 2016.

[11] J.W. Bennett, B.C. Mecrow, D.J. Atkinson, et al. "Safety-critical design of electromechanical actuation systems in commercial aircraft", in IET Electric Power Applications, vol. 5, n. 1, 2011.

[12] S.A. Odhano, P. Giangrande, R. Bojoi, and C. Gerada, "Selfcommissioning of interior permanent magnet synchronous motor drives with high-frequency current injection," in 2013 Energy Conversion Congress and Exposition, pp. 3852-3859, 2013.

[13] C. Sciascera, P. Giangrande, C. Brunson, M. Galea and C. Gerada, "Optimal design of an electro-mechanical actuator for aerospace application," in 2015 Annual Conference of the IEEE Industrial Electronics Society, pp. 1903-1908, 2015.

[14] J.C. Derrien, "EMA advanced technologies for flight controls", in International Congress of the Aeronautical Sciences, 2012.

[15] M. Todeschi, "Airbus - EMAs for flight controls actuation system 2012 status and perspectives", in Recent Advances in Aerospace Actuation Systems and Components, 2012.

[16] M.A. Ismail, E. Balaban, et al. "Fault detection and classification for flight control EMA", in IEEE Aerospace Conference, 2016.

[17] G. Qiao, G. Liu, Z. Shi, et al., "A review of EMAs for More/All Electric aircraft systems", in Journal of Mechanical Engineering Science, 2017.

[18] A. Al-Timimy, P. Giangrande, M. Degano, Z. Xu, M. Galea, C. Gerada, G. Lo Calzo, H. Zhang, and L. Xia, "Design and losses analysis of a high power density machine for flooded pump applications," in IEEE Trans. On Industry Applications, vol. 54, no. 4, pp. 3260-3270, 2018.

[19] A. Al-Timimy, G. Vakil, M. Degano, P. Giangrande, C. Gerada, and M. Galea, "Considerations on the effects that core material machining has on an electrical machine's performance," in press on IEEE Transaction on Energy Conversion, 2018, DOI: 10.1109/TEC.2018.2808041.

[20] A. Al-Timimy, M. Alani, M. Degano, P. Giangrande, M. Galea, and C. Gerada, "Influence of rotor endcaps on the electromagnetic performance of high speed PM machine", in press on IET Electric Power Applications, 2018, DOI: 10.1049/iet-epa.2017.0811.

[21] P.Giangrande, C.I.Hill, S.V.Bozhko, and C. Gerada, "A novel multi-level electro-mechanical actuator virtual testing and analysis tool," in 2014 IET Conference on Power Electronics, Machines and Drives, pp. 1-6, 2014.

[22] A. Al-Timimy, P.Giangrande, M. Degano, M. Galea and C. Gerada, "Comparative study of permanent magnet-synchronous and permanent magnet-flux switching machines for high torque to inertia applications," in 2017 IEEE WEMDCD, pp. 45-51, 2017.

[23] H.V. Xuan, D. Lahaye, H. Polinder, "Influence of slot/pole number combination on performances of permanent magnet machines with concentrated windings for ship application", in International Conference on Electrical Machines and Systems, 2011.

[24] J. Gao, Y. Yu and S. Huang, "Winding layers and slot/pole combination in fractional slot/pole PMSM - Effects on motor performance", in International Conference on Electrical Machines and Systems, 2009.

[25] Z. Xu, A. Al-Timimy, M. Degano, P. Giangrande, G. Lo Calzo, H. Zhang, M. Galea, C. Gerada, S. Pickering, and L. Xia, "Thermal management of a permanent magnet motor for a directly coupled pump," in 2016 International Conference on Electrical Machines, pp. 2738-2744, 2016.

[26] C. Sciascera, M. Galea, P. Giangrande, and C. Gerada, "Lifetime consumption and degradation analysis of the winding insulation of electrical machines", in 2016 IET International Conference on Power Electronics Machines and Drives, pp. 1-6, 2016.

[27] F. Cupertino, G. Pellegrino, P. Giangrande, and L. Salvatore, "Model based design of a sensorless control scheme for permanent magnet motors using signal injection," in 2010 IEEE Energy Conversion Congress and Exposition, pp. 3139-3146, 2010.

[28] P. Giangrande, F. Cupertino and G. Pellegrino, "Modelling of linear motor end-effects for saliency based sensorless control", in 2010 IEEE Energy Conversion Congress and Exposition, pp. 3261-3268, 2010. 